\title{
O RECONHECIMENTO DOS DIREITOS DOS POVOS INDÍGENAS: UM ESTUDO À LUZ DAS CONSTITUIÇÕES BRASILEIRAS
}

\section{THE RECOGNITION OF THE RIGHTS OF INDIGENOUS PEOPLES: A STUDY IN THE LIGHT OF THE BRAZILIAN CONSTITUTIONS}

\section{HELENICE DA APARECIDA DAMBRÓS BRAUN}

Doutora e mestre em Direito pela Universidade Federal em Santa Catarina (UFSC). Graduação em Ciências Jurídicas e Sociais pela Universidade do Vale do Rio dos Sinos (Unisinos), em São Leopoldo (RS). Cursos de Especializações Lato Sensu de Pós-Graduação em Direito Político pela Unisinos, Direito Processul Civil pela Universidade do Oeste Catarinense (Unoesc) e Docência na Educação Superior pela Unochapecó, em Chapecó (SC). Membro da Rede de Estudos em Relações Internacionais (REdRI).

\section{ODETE MARIA DE OLIVEIRA}

Pós-Doutora em Estudos Comunitários Europeus pela Universidad Complutense de Madrid-Espanha. Doutora e Mestre em Direito pela Universidade Federal de Santa Catarina (UFSC). Mestre em Psicologia Transpessoal pela ALUBRAT (BrasilPortugal). Pesquisadora da Fondazione Cassamarca de Treviso-Itália. Líder do Grupo de Pesquisa Relações Internacionais, Direito e Poder. Coordenadora da Rede de Estudos em Relações Internacionais (REdRI). Professora Titular (aposentada) da UFSC e Professora Titular do Curso de Mestrado em Direto da Universidade Comunitária da Região de Chapecó (Unochapecó).

FLORISBAL DEL'OLMO Pós- Doutor em Direito (UFSC). Doutor em Direito (UFRGS). Mestre em Direto (UFCS). Especialista em Direito e Educação. Professor do Programa de Mestrado e 
Doutorado em Direito na URI. Santo Ângelo(RS). Líder do Grupo de Pesquisa certificado no CNPq -Tutela dos Direitos e sua Efetividade. Coordenador do Projeto de Pesquisa Direito Internacional do Trabalho e o Resgate da Dignidade e da Cidadania. Membro-Associado da Rede de Estudos de em Relações Internacionais (REdRI).

\section{RESUMO}

O objetivo deste artigo é analisar o reconhecimento dos direitos dos povos indígenas, apresentando-se uma abordagem sobre as constituições brasileiras, em especial atenção à Constituição Federal de 1988, indagando-se como as constituições brasileiras atuaram quanto à aos direitos de proteção e garantia dos povos Indígenas, bem como se as diversas reformas constitucionais ocorridas ao longo dos anos introduziram o reconhecimento dos direitos desses povos e o reconhecimento da autodeterminação da nação indígena.

Metodologia: A metodologia segue o método dedutivo, utilizando-se de leituras e consultas em obras, artigos e sites da Internet.

Resultados: Embora haja legislação vigente no País para tratar dos direitos dos povos indígenas, percebe-se uma grande lacuna entre a teoria e a prática, legitimada principalmente pela postura da sociedade envolvente, que continua visualizando os indígenas como povos inferiores. São inúmeras as dificuldades enfrentadas pelos povos indígenas para assegurar seus direitos frente ao poderio econômico, que desconsidera 0 seu direito originário sobre as terras que tradicionalmente ocupam.

Contribuições: As principais contribuições deste estudo externam que na sociedade brasileira ainda há preconceito, discriminação e exclusão do indígena; é preciso avançar para que sejam respeitados os direitos desses povos em manter e reforçar suas próprias instituições, culturas e tradições, além de prosseguir com seu desenvolvimento em sintonia com suas necessidades e aspirações.

Palavras-chave: Direitos indígenas; povos indígenas; constituições brasileiras; Constituição Federal de 1988. 


\begin{abstract}
Objective: To analyze the recognition of the rights of indigenous people, presenting an approach on Brazilian constitutions, with special attention to the Federal Constitution of 1988, understanding how the Brazilian constitutions acted on the rights of protection and guarantee of Indigenous people, as well as whether the various constitutional reforms that occurred over the years introduced the recognition of the rights of these people and the recognition of the indigenous nation's selfdetermination.
\end{abstract}

Methodology: The deductive method, using readings and consultations in works, articles and Internet sites.

Results: Although there are legislation in force in the Brazil to deal with the rights of indigenous people, there is a great gap between theory and practice, legitimized mainly by the posture of the society, which continues to view indigenous people as inferior. There are countless difficulties faced by indigenous people to ensure their rights in the face of economic power, which disregards their original right to the lands they traditionally occupy.

Contributions: The main contributions of this study show that in Brazilian society there is still prejudice, discrimination and exclusion of indigenous people; it is necessary to move forward to respect the rights of these people and strengthen their own institutions, cultures and traditions in addition to continuing their development in line with their needs and aspirations.

Keywords: Indigenous rights; indigenous people; Brazilian constitutions; 1988 Federal Constitution

\title{
INTRODUÇÃO
}

O estudo ocupa-se com a luta e conquista dos Povos Indígenas no Brasil em busca da garantia de seus direitos. Na realidade, lutam pelo reconhecimento de vários direitos, entre eles, encontram-se questões sobre a propriedade de suas próprias terras usurpadas, pela participação de suas comunidades em diferentes esferas de decisão do governo, respeito as suas práticas culturais e memórias de seus antepassados. Em que pesem os avanços constitucionais e normativos brasileiros, registram-se desafios a sua concretização. 
Nesse sentido, como objeto de conhecimento deste estudo, o presente ensaio dedica-se a abordagens sobre as Constituições brasileiras, detendo atenção à Constituição Federal de 1988, indagando como perguntas de sua pesquisa: Como as Constituições brasileiras atuaram quanto à constituição dos direitos de proteção e garantia dos Povos Indígenas? As diversas reformas constitucionais ocorridas a longo dos anos introduziram o reconhecimento dos direitos dos Povos Indígenas e o reconhecimento da autodeterminação da nação indígena? Os dispositivos inseridos nos textos das Constituições brasileiras permitiram aos Povos Indígenas avançar efetivamente com demandas de proteção à diversidade étnica, específica cultura, tradição, memória dos seus antepassados e garantia dos territórios da nação indígena?

Desse modo, a temática deste estudo é relevante, aborda sobre os Povos Indígenas, sujeitos envolvidos com a questão dos seus próprios e específicos direitos, não apenas formalmente assinalados na Constituição brasileira em vigor, mas também com o cotidiano material desses povos.

Nesse viés, o tema central da pesquisa concentra-se no âmbito dos direitos dos Povos Indígenas, delimitando-se na órbita constitucional e dos instrumentos de ordenação normativa de reconhecimento e de proteção atualmente em vigor nesse sentido, direcionando-se a observar se tais direitos são efetivados. Para atender ao objetivo geral ora proposto, o tema é apresentado a partir de objetivos específicos ordenados em três partes. Inicialmente, são anotados evidencias e dados sobre 0 universo dos Povos Indígenas, visando oferecer uma melhor compreensão aos leitores sobre o assunto. $\mathrm{Na}$ continuidade, focaliza-se a evolução das Constituições brasileiras, especificamente observando-se o tipo de atenção dada aos direitos de proteção aos Povos Indígenas. Finalmente, a última parte concerne destaque para os preceitos normativos previstos na atual Constituição Federal de 1988 e seus efeitos.

Como orientação desta pesquisa, formulam-se aqui indagações: Quem são os Povos indígenas? Podem ser identificados como aqueles povos que descendem de populações que existiam antes dos Estados atuais, que conservam totalmente ou 
parcialmente as suas instituições sociais, políticas, culturais e modo de viver, que têm autoconsciência da sua própria identidade. Ou seja, são considerados indígenas pelo fato de descender de populações que habitam o país ou região geográfica e que pertenceram ao país na época da conquista, ou da colonização, ou do estabelecimento das atuais fronteiras, independentemente da sua situação jurídica e conservam as suas próprias instituições sociais, econômicas, políticas, culturais, ou parte delas.

Já, os direitos indígenas referem-se aos direitos coletivos existentes, que reconhecem a condição dos povos indígenas. Os direitos indígenas no Brasil são direitos coletivos e podem ser classificados em direitos territoriais, direitos à diversidade étnico-cultural, direito à auto-organização e direito à diferença. Os novos direitos indígenas são aqueles direitos previstos a partir da Constituição Federal de 1988, em que há efetivamente a participação dos diretamente interessados - os indígenas.

Dessa forma e nesse ensaio, o destaque em termos de legislação brasileira direciona-se à questão constitucional - abordagens nas diferentes Constituições brasileiras - com ênfase na Constituição Federal de 1988, observando-se como hoje considerados e tratados os direitos dos Povos Indígenas - até então vistos como atores invisíveis, inexistentes e sem importância - à conquista do reconhecimento de sujeitos de seus próprios interesses.

Apesar da importância das disposições contidas na legislação do Estatuto do Índio, Lei n. 6001, de 19 de dezembro de 1973, apresentando pela primeira vez os conceitos de comunidade indígena e grupo tribal em nosso país, permitindo aos Povos Indígenas postular diretamente em juízo os seus direitos, observa-se que esse assunto não será objeto deste estudo. O método de abordagem utilizado é o hipotético dedutivo, partindo do geral para o particular, por meio de raciocínio descendente com base em teorias ou leis, com objetivo de chegar a uma conclusão. Quanto às técnicas de pesquisa, utilizam-se leituras e consultas em obras, artigos e 
sites da Internet. ${ }^{1}$

\section{BREVE PANORAMA SOBRE A REALIDADE DOS POVOS INDÍGENAS}

O modo de viver dos Povos Indígenas apresenta características e especificidades próprias e que os diferenciam de outros povos. Trata-se de uma de cosmovisão e forma de vida naturalista alternativa apresenta-se completamente diversa do modelo ocidental capitalista e da cultura eurocêntrica.

A relação dos Povos Indígenas com a natureza, a terra, a espiritualidade e a comunidade são diversas dos desenhos do ocidente. Nesse sentido, ostentam diferentes concepções sobre o conhecimento, a memória, o tempo e o espaço. Essas concepções estão presentes nas suas reivindicações e de certa forma constituem uma crítica ao modo de vida ocidental e seus valores, como a propriedade privada, a mercancia dos bens e da terra. Na forma de viver dos povos indígenas o que prevalece é o coletivo e a comunidade, em contraponto com o individualismo e o liberalismo.

Neste tópico objetiva-se apresentar dados sobre os Povos Indígenas em nível nacional, com a finalidade de situar o leitor sobre a realidade indigenista brasileira.

\subsection{DADOS SOBRE O UNIVERSO DA POPULAÇÃO INDÍGENA}

No presente estudo, inicialmente é fundamental trazer dados sobre a população indígena do Brasil, para compreender o desafio da relevante atuação e o papel dos Povos Indígenas na luta por conquista de seus direitos.

Nos séculos 15 e 16 a população indígena na América era estimada em mais de 100 milhões de indígenas. Até a metade do século 17 essa população foi

\footnotetext{
1 Artigo elaborado com base em dados da seguinte pesquisa: BRAUN, Helenice da Aparecida Dambrós. Os indígenas e seus direitos trabalhistas: uma análise de demandas judiciais de comunidades em Chapecó. Curitiba: Editora CRV, 2017.
} 
reduzida em 95\%, em razão de diversas causas, como as guerras, a destruição do meio ambiente, as doenças, entre outros.

Estima-se, que neste século 21, a população indígena na América seja de 40 milhões, com maior concentração nos países da Bolívia, Equador, Guatemala, México e Peru, formando aproximadamente quatrocentos povos. No Brasil, em 1990, a população indígena contava 200 mil, com 150 grupos e 170 línguas diferentes. No ano de 1997 a população alcançou o número de 350 mil indígenas, que representa um percentual de $0,2 \%$ da população brasileira. São 206 grupos distribuídos em 546 áreas diferentes, falando 270 línguas (IKAWA, 2010, p. 497499).

Como anota Curi $(2010$, p. 1), "ao contrário do que se previa o índio brasileiro não se transformou em 'branco', nem foi totalmente exterminado, mas iniciou, nas últimas décadas, um lento processo de recuperação demográfica". Nesse sentido, de acordo com dados da FUNAI (2019), desde 1500 até a década de 1970, a população indígena brasileira decresceu acentuadamente e muitos povos foram extintos. O desaparecimento dos povos indígenas passou a ser visto como uma contingência histórica, algo a ser lamentado, porém inevitável. No entanto, esse quadro começou a dar sinais de mudança nas últimas décadas do século passado.

A partir de 1991, o IBGE incluiu os indígenas no censo demográfico nacional. O contingente de brasileiros que se consideravam indígenas cresceu $150 \%$ na década de 90. O ritmo de crescimento foi quase seis vezes maior que o da população em geral. O percentual de indígenas em relação à população total brasileira saltou de 0, 2\% em 1991 para 0,4\% em 2000, totalizando 734 mil pessoas. Houve um aumento anual de $10,8 \%$ da população, a maior taxa de crescimento dentre todas as categorias, quando a média total de crescimento foi de 1,6\%" (FUNAI, 2016). Sem pontuar que "além da dificuldade de assegurar os direitos e interesses dos povos indígenas frente ao poderio econômico, que desconsidera o direito originário desses povos sobre as terras que tradicionalmente ocupam, a sociedade ocidental continua enxergando os indígenas como povos inferiores" (CURI, 2010, p. 4). 
De acordo com dados do Censo Demográfico realizado pelo IBGE, em 2010, a população indígena brasileira era de 896,9 mil indígenas, o que representava $0,47 \%$ da população brasileira. Esse estudo identificou 305 etnias, das quais a maior era a Tikúna, com $6,8 \%$ da população indígena. Também foram reconhecidas 274 línguas. Dos indígenas com 5 anos ou mais de idade, 37,4\% falavam uma língua indígena e 76,9\% falavam português.

A etnia Tikúna tinha o maior número de indígenas $(46,1$ mil), resultado influenciado por $85,5 \%$ deles que residiam em terras indígenas. Os indígenas da etnia Terena estavam em maior númeroefora das terras (9,6 mil). Nas terras indígenas, as etnias Yanomámi, Xavante, Sateré-Mawé, Kayapó, Wapixana, Xacriabá e Mundurukú não estavam presentes nas 15 mais enumeradas fora das terras. Já, fora das terras, não coincidentes eram Baré, Múra, Guarani, Pataxó, Kokama, Tupinambá e Atikum (PORTAL BRASIL, 2019).

Neves (2003, p. 113) informa que é no Estado do Amazonas que há o maior número de etnias, o maior contingente populacional indígena, o maior número de organizações indígenas e o maior número de terras indígenas. Os povos indígenas estão presentes nas cinco regiões do Brasil. A maior concentração está na região Norte com 342,8 mil indígenas e com menor no Sul, 78,8 mil. Do total de indígenas no Brasil, 502.783 vivem na zona rural e 315.180 habitam as zonas urbanas brasileiras. Quanto ao local, a pesquisa constatou que 36,2\% dos indígenas vivem em área urbana e $63,8 \%$ na área rural. O total inclui os 817,9 mil indígenas declarados no quesito cor ou raça do Censo 2010 (e que servem de base de comparações com os Censos de 1991 e 2000) e também as 78,9 mil pessoas que residiam em terras indígenas e se declararam de outra cor ou raça (principalmente pardos, 67,5\%), mas se consideravam "indígenas" de acordo com aspectos como tradições, costumes, cultura e antepassados (PORTAL BRASIL, 2019).

Quanto ao sexo, a pesquisa revelou equilíbrio entre o número de mulheres e homens: 100,5 homens para cada 100 mulheres, com mais mulheres nas áreas urbanas e mais homens nas rurais. Já, nas áreas rurais há um declínio no predomínio masculino entre 1991 e 2010, especialmente no Sudeste (de 117,5 para 
106,9). Norte (de 113,2 para 108,1) e Centro-Oeste (de 107,4 para 103,4).

No tocante às questões de demarcação de terras, o censo constatou que foram demarcadas 505 terras indígenas, cujo processo de identificação teve a parceria da FUNAI no aperfeiçoamento da cartografia. Essas terras representam $12,5 \%$ do território brasileiro (106,7 milhões de hectares), onde residiam 517,4 mil indígenas ( $57,7 \%$ do total). Apenas seis terras tinham mais de 10 mil indígenas, 107 tinham entre mais de mil e 10 mil, 291 tinham entre mais de cem e mil, e em 83 residiam até cem indígenas. A terra com maior população indígena é a Yanomami, no Amazonas e, em Roraima, com 25,7 mil indígenas, 5\% do total (PORTAL BRASIL, 2019).

O Censo de 2010, realizado pelo Instituto Brasileiro de Geografia e Estatística (IBGE), revelou dados importantes e mais atuais sobre a população indígena brasileira. Estes dados identificam quais são as principais etnias, local em que vivem e a situação das terras indígenas, entre outros dados importantes, por exemplo, a população indígena soma 896.917 pessoas $(0,47 \%$ da população brasileira), as 505 terras indígenas correspondem a 12, 5\% do território brasileiro. Nestas terras vivem 517.383 índios (57,7\% de todos os indígenas). A quantidade de etnias perfazem o total de 305, assim ilustradas, as maiores etnias são Tikúna (46 mil), Guarani Kaiowá (43,4 mil), Kaingang (37,4 mil), Makuxí (28,9 mil), Terena (28,8 mil) e Tenetehara (24,4 mil). Com relação às línguas observam-se 274. Os indígenas encontram-se distribuídos em zonas rurais $(63,8 \%)$ e em zonas urbanas $(36,2 \%)$, vivendo por região. Na região Norte $(38,2 \%)$, Nordeste $(25,9 \%)$, Centro-Oeste (16\%), Sudeste $(11,1 \%)$, Sul $(8,8 \%)$. Quanto os Estados com maiores concentrações de índios citam-se o Amazonas (20,5\%), Mato Grosso do Sul (8, 6\%), Pernambuco (6, $8 \%)$ e Bahia $(6,7 \%)$ e como terras indígenas mais populosas enumera-se Yanomami (Amazonas e Roraima), com 25.719; Raposa Serra do Sol (Roraima), com 17.102; Évare I (Amazonas), com 16.686. A taxa de alfabetização indígena (15 anos de idade ou mais), um percentual de $76,7 \%$. Já os principais troncos linguísticos (falantes com mais de 5 anos de idade), Tikúna (34,1 mil falantes), Guarani Kaiowá 
(25,5 mil falantes), Kaingáng (22 mil falantes), Xavante (12,3 mil falantes). ${ }^{2}$

Conforme estudos da FUNAl, os dados do Censo Demográfico de 2010, realizado pelo IBGE, revelaram que em todos os Estados da Federação, inclusive do Distrito Federal, há populações indígenas. A FUNAl também registra 69 referências de índios ainda não contatados, além de existirem grupos que requerem o reconhecimento de sua condição indígena junto ao órgão federal indigenista.

Esta população, em sua grande maioria, vem enfrentando uma acelerada e complexa transformação social, necessitando buscar novas respostas para a sua sobrevivência física e cultural e garantir para as próximas gerações melhor qualidade de vida. Nas comunidades indígenas constatam-se problemas concretos, tais como invasões, degradações territoriais e ambientais, exploração sexual, aliciamento e uso de drogas, exploração de trabalho, inclusive infantil, mendicância, êxodo desordenado, o que vêm causando grande concentração de indígenas nas cidades.

Como afirma Henriques (2014, p. 58), após séculos de opressão, marginalização e etnocídio, é notável a emergência de vários níveis dos Povos Indígenas no final do século 20. Esses povos possuem especificidades oriundas dos seus modos de vida e suas culturas e que por isso repercutem nos seus direitos, lutas e reivindicações. Na sequência será iniciada a abordagem sobre os direitos indigenistas e as Constituições brasileiras.

\section{OS DIREITOS DOS POVOS INDÍGENAS E AS CONSTITUIÇÕES BRASILEIRAS}

Neste tópico será dada ênfase a abordagens sobre os direitos indígenas decorrentes de determinações em dispositivos das Constituições brasileiras, iniciando-se pela primeira delas, conhecida como a Carta histórica de 1824 . Na

2 Ver: Censo IBGE2010. Disponível em: <http://indigenas.ibge.gov.br/grafico-e-tabelas-2.html>. Acesso em: 14 abril 2019. 
sequência serão focalizados os magnos documentos constitucionais de 1934 e 1937 (Polaca), após as Constituições de 1946, 1967 e 1969. A Constituição de 1988 será apresentada no último tópico deste estudo.

\subsection{CARTA HISTÓRICA DE 1824}

A primeira Constituição brasileira de 1824 não fazia qualquer referência à existência dos índios, embora no Projeto de Constituição de 1823 houvesse mostrado pequena preocupação em estabelecer locais, para que se pudesse realizar a catequese e a "civilização" dos índios. Em 1834, por meio de Ato Institucional estabeleceu-se que a competência para promover a catequese, civilização dos índios e o estabelecimento das colônias seria competência das Assembleias Legislativas Provinciais e dos Governos Gerais (BRAUN, 2017, p. 80).

Em 1890 foi feito um documento de ordem constitucional chamado Proposta Constitucional de 1890. Nesse documento estavam presentes as ideias positivistas Ordem e Progresso - de Augusto Comte (1976), materializadas por meio de proposta da convivência pacífica e da miscigenação entre o europeu, o negro e o índio.

\subsection{CARTAS DA DÉCADA DE 30}

A Constituição de 1934 foi a primeira Carta constitucional que trouxe dispositivos sobre a ordem econômica e social, resultado da tendência europeia do pós-guerra, estabelecendo direitos sociais, com uma legislação trabalhista que garantia a autonomia sindical, uma jornada de trabalho de oito horas, a previdência social e os dissídios coletivos. Conforme Bonavides e Andrade (1991, p. 320, 326), a Constituição de 1934 tinha uma natureza dúbia, marcada por indecisões e ambiguidades, por uma síntese entre elementos do pensamento liberal e tendências intervencionistas do Estado. Mas, não há dúvida que a grande temática recaiu sobre o Estado Social. 
Na Constituição de 1934 fixou-se a competência da União, para legislar sobre a integração do índio à comunidade nacional.

Em 1934 iniciou a discussão em foro constitucional sobre a comunhão nacional dos indígenas, com sua gradual incorporação com a permissão da União em legislar sobre a incorporação dos silvícolas à comunhão nacional, artigo 5, XIX da Constituição Federal de 1934. Esse artigo estava em consonância com os objetivos evolucionistas do Serviço de Proteção do Índio, revigorando a noção de que a sociedade indígena não era desenvolvida. Mais uma vez se evidencia que a cultura indígena não era considerada, excluída pela assimilação da cultura oficial, devendo ser incorporada à nacional.

A Constituição de 1934 também estabeleceu outro artigo vinculado à questão indígena, que inseriu um aspecto novo sobre 'terras tradicionalmente ocupadas pelos índios', no artigo 129, com o seguinte teor "será respeitada a posse de terras de silvícolas que nelas se achem permanentemente localizados, sendoIhes, no entanto, vedado aliená-las". O objetivo dos parlamentares constituintes da época era facilitar o processo de catequese dos índios dentro do contexto da integração a que estavam submetidos (BECKHAUSEN, 2010, p. 532). Nessa Carta constitucional ficou garantida a posse da terra, no local em que os silvícolas se achassem localizados e proibiu-se a alienação dessas terras.

Já, a Constituição de 1937 foi uma Carta outorgada. O golpe de 10 de novembro de 1937 fez com que se impusesse no país, Carta constitucional diferente daquela Carta de 1934, que nasceu da Assembleia Nacional Constituinte, e no momento político em que "no cadinho das agitações sociais, num período de vizinhança do desenvolvimento industrial que se pronunciava, o fantasma do comunismo foi fonte alimentadora do golpe e, portanto, da Carta de 37" (BONAVIDES; ANDRADE, 1991, p. 340). A ideologia da Constituição de 1937 era de origem autoritária.

A Constituição de 1937 estabeleceu no artigo 154, que "Será respeitada aos silvícolas a posse das terras em que se achem localizados em caráter permanente, sendo-Ihes, no entanto, vedado aliená-las." Foi realizada uma pequena mudança, ou 
seja, apenas retirou do texto a tese de comunhão nacional e com relação à posse da terra ficou como na Constituição de 1934.

\subsection{CARTA DA DÉCADA DE 40}

A Constituição de 1946 foi fruto de uma Assembleia Constituinte legítima, sob o ponto de vista dos pressupostos formais de convocação, com perfil inovador em aspectos sociais. Considerada a mais avançada até aquele momento, votada em Assembleia Nacional Constituinte e promulgada no mês de setembro, foi notadamente um "avanço da democracia".

A bancada Constituinte foi elaborada por Eurico Gaspar Dutra, então presidente e, neste sentido, o documento trazia de volta liberdades expressas na Constituição de 1934, que haviam sido retiradas do texto constitucional de 1937 devido ao golpe do Estado Novo. Dentre os dispositivos básicos que retornavam ao texto depois de um período ditatorial estavam: a igualdade de todos perante a lei; a inviolabilidade do sigilo de correspondência; a liberdade de consciência, de crença e de exercício de cultos religiosos; a separação dos três poderes (legislativo, executivo, judiciário); entre outros termos. No entanto, mesmo com toda a campanha otimista que cercava essa Constituição, o texto de integração do índio à comunhão nacional da Carta de 1934 foi novamente repetido (LOPES, 2019, p. 90).

A Carta Constitucional foi promulgada em 18 de setembro de 1946, mantendo os mesmo artigos da constituição de 34: "Art. $5^{\circ}$ - Compete à União: [...] XV - legislar sobre: $r$ ) incorporação dos silvícolas à comunhão nacional." No artigo 216, estabelecia que "Será respeitada aos silvícolas a posse das terras onde se achem permanentemente localizados, com a condição de não a transferirem."

Garantiu aos silvícolas o direito de terra vedando sua alienação e sendo competência exclusiva da União legislar sobre a incorporação dos silvícolas a sociedade. Em todas as legislações que resguardava direitos aos indígenas sempre manteve o caráter integracionista.

A Carta Constitucional de 1946 praticamente repetiu o que estava previsto 
no artigo 154 da Constituição Federal de 1937 e retornou a competência da União para legislar sobre a questão "comunhão", o que se denota, mais uma vez, o desrespeito à cultura indígena e também se referia ao direito à posse da terra.

\subsection{CARTAS DA DÉCADA DE 60}

O Projeto Constitucional de 1967 também previa a competência da União para legislar sobre as questões dos indígenas à comunhão nacional. Já as Emendas Constitucionais definem a terra como "patrimônio", que não poderá ser alienado, mas os índios têm o direito de usufruto sobre os recursos naturais da terra. A Carta Constitucional de 1967 manteve os mesmos princípios no que diz respeito à competência da União e ao usufruto. Neste aspecto amplia sobre o usufruto dos recursos naturais e de todas as suas utilidades.

A Constituição de 1967 também repetiu a visão integracionista, só alterou o nome comunhão para comunidade. No artigo 4ํㅡㄹ inciso IV, estabeleceu que as terras indígenas são do patrimônio da União, e os indígenas que habitam essas terras são considerados como possuidores e usufrutuários.

Nesse contexto histórico dos direitos dos indígenas, é necessário abrir um parêntese e citar a criação de um órgão voltado especificamente para tratar das questões indígenas chamado de Fundação Nacional do Índio (FUNAI).

A FUNAI foi criada em 5 de dezembro de 1967, por meio da Lei n. 5.371, de 1967, para dar continuidade às atribuições que pertenciam anteriormente ao Serviço de Proteção ao Índio (SPI) ${ }^{3}$. A fundação dessa autarquia federal se deu no período do regime militar no Brasil e, como já destacado anteriormente, os indígenas eram considerados pelo governo e por parte da sociedade, como obstáculo ao desenvolvimento nacional (BRAUN, 2017, p. 82).

As atribuições e atividades principais da FUNAI consistem no "resguardo à aculturação espontânea do índio, de forma que sua evolução socioeconômica se processe a salvo de mudanças bruscas; promover a educação de base apropriada 
do índio visando à sua progressiva integração na sociedade nacional e outras" (BRAUN, 2017, p. 82-83).

Constata-se na Constituição de 1967, que os textos formalmente liberais colidiam com a realidade da ditadura e inúmeros dispositivos autoritários, em que o poder executivo poderia se sobrepor aos poderes legislativo e judiciário. A Carta de 1967 trouxe inovações. No entanto, a preocupação do governo autoritário da época era de se perpetuar, criando a Emenda n. 1, de 1969, uma nova Carta com adaptação dos vários atos institucionais e complementares.

Por seu turno, a Constituição de 1969 - denominada Ato Institucional 1 ampliou em alguns aspectos os direitos indígenas. Incluiu como bens da União as terras ocupadas pelos silvícolas, sendo de sua posse permanente e alienável, mantendo o usufruto das riquezas naturais e de suas utilidades e a competência da União para legislar sobre a incorporação dos silvícolas à comunidade nacional.

A citada Emenda Constitucional n. 1, de 1969, introduziu no texto dessa Carta um dispositivo que declarava como parte do território da União as terras indígenas, o que, em regra, afastava o processo de esbulho que os estados vinham realizando, e centralizou a questão indígena na esfera federal. Também reconheceu, aos indígenas, o direito ao usufruto exclusivo de recursos naturais existentes em suas terras, podendo eles buscar juridicamente seus direitos nos casos de desrespeito ao meio ambiente, prática muito comum de fazendeiros, empresas mineradoras e de representantes de órgãos governamentais.

No que concerne à questão das terras indígenas, segundo Araújo (2006, p. 29) durante o regime e o governo militar no Brasil, que perdurou de 1964 a 1985 , percebe-se que no plano legal e político ocorreram algumas medidas importantes para os povos indígenas, embora tenham sido aplicadas de forma distorcida e equivocada.

Em suma, verifica-se que em todas essas Cartas constitucionais, a ideologia e a política indigenista estavam sempre direcionadas à questão da integração do indígena à comunidade nacional, não havia preocupação com a cultura indígena e sequer se reconhecia as diferenças étnicas. A seguir dar-se-á atenção ao estudo da 
Constituição de 1988, observando-se o alcance de suas disposições sobre os direitos dos Povoa Indígenas.

\section{OS DIREITOS DOS POVOS INDÍGENAS E A CONSTITUIÇÃO DE 1988}

No decorrer da história dos Povos Indígenas verifica-se que os seus direitos eram praticamente inexistentes. Ainda no século 19 eram poucos, se restringiam aos direitos de liberdade e de igualdade. Esses direitos poderiam ser "exercidos" somente na hipótese de os índios optarem por não serem mais indígenas. A partir do século 20 , devido às lutas e disputas e depois de terem perdido grande parte de seus territórios e suas tradições, é que ocorreu o reconhecimento de alguns direitos coletivos.

Os Estados constituídos na América Latina sempre ocultaram a existência dos povos indígenas, que já viviam em seus espaços territoriais. A explicação dessa invisibilidade decorria do modelo de constituições vigentes a partir do século 19. Essas Constituições tinham como desenho aquelas da Europa, que reconheciam apenas o indivíduo (o sujeito) como titular de direitos. Partindo desse formato, o coletivo - plural - teria que ser enquadrado dentro do individual e todos os direitos deveriam ter como legitimidade um contrato entre homens livres. "Os povos, comunidades, organizações e grupos sociais diferentes foram desconsiderados em nome do indivíduo e sua liberdade, na ideia de que o reconhecimento do coletivo restringiria a liberdade individual" (SOUZA FILHO, 2010, p. 479).

$\mathrm{Na}$ segunda metade do século 20 é que foram inseridos alguns direitos coletivos nas Constituições da América Latina, com mais veemência a partir dos anos 80 , frisa-se que esses direitos só foram reconhecidos devido às lutas $\mathrm{e}$ disputas dos Povos Indígenas por territórios e pela manutenção de suas tradições.

A Constituição do Brasil de 1988, denominada Carta Cidadã, promoveu diversos avanços no que diz respeito aos direitos humanos fundamentais e nesse processo a grande expectativa de mudança era em torno da proteção e garantia dos 
direitos dos Povos Indígenas.

Durante o processo constituinte foi extremamente acentuado o movimento dos Povos Indígenas para a inclusão de seus direitos fundamentais na Constituição de 1988, isso fez com que ficasse mais evidente e contundente o grande distanciamento das desigualdades sociais, culturais, econômicas e políticas, além da discriminação e preconceitos existentes na sociedade brasileira em relação com os indígenas. Durante o processo constituinte os índios encontravam-se nos meios de comunicação lutando e defendendo seus direitos, buscando prioridade nas políticas públicas e participação no orçamento do país. A Carta Constitucional de 1988 trata dos direitos indígenas em vários dispositivos.

No que concerne aos direitos reconhecidos pelo Estado aos Povos Indígenas no Brasil, a Carta de 1988 prevê essa matéria em um capítulo específico, no Título VIII, Capítulo VIII, artigos 231 e 232. No capítulo VIII, que trata especificamente Dos Índios, afasta a doutrina da assimilação natural, reconhecendo direitos inerentes aos povos indígenas, direitos derivados de seu status como ocupantes iniciais das terras brasileiras.

A Constituição de 1988 foi a primeira Carta constitucional na América Latina, a reconhecer que os Povos Indígenas são um grupo diferenciado na sociedade brasileira, estabelecendo seus direitos sociais e territoriais. Reconhece, igualmente, que o Brasil é um país multicultural e pluriétnico. Segundo Souza Filho (2010, p. 487), "a Constituição reconhece como legítima uma ordem que desconhece, já que fundada nos chamados usos, costumes e tradições". Mas, essa ordem pode ser descrita por um especialista, isto é, por um cientista, sociólogo ou antropólogo, por um membro da comunidade, é uma ordem social própria e diversa daquela ordem jurídica estatal organizada pela Constituição, e o mais importante "reconheceu povos socialmente organizados fora do paradigma da modernidade" (SOUZA FILHO, 2010, p. 487). Esse é ponto fundamental, a grande diferença, a quebra de paradigma, o total rompimento com as ideologias do passado, que cada povo que mantenha sua organização social seja reconhecido.

No que diz respeito aos Povos Indígenas, é necessário diferenciar dois 
direitos distintos, um que pertence a toda a humanidade, e outro que pertence a cada povo. O primeiro é denominado direito à sociodiversidade, direito de todos à existência e manutenção dos diversos povos e suas culturas. Obriga cada povo e cada Estado respeitar o Outro. Esse direito está previsto nas Constituições internas de cada Estado e tratados internacionais. É um direito à alteridade com vínculos no direito à biodiversidade. $\mathrm{O}$ segundo é um direito coletivo, o direito que tem como sujeito os próprios povos a sua existência, pertence a um determinado povo. É um direito indivisível entre os seus titulares, não podem ser alienados, são imprescritíveis, impenhoráveis e intransferíveis. Esses direitos na Carta de 1988 apresentam-se em três dimensões: os territoriais, de organização social e os de cultura. Ressalta-se, que a violação de uma dimensão também violará as demais (SOUZA FILHO, 2010, p. 494-495).

A relevância da inclusão desses direitos está naqueles artigos que possuem uma formatação não integracionista, em especial, a autodeterminação nas esferas cultural e territorial. Essas inovações constitucionais serão pontuadas nos próximos subitens.

\subsection{DIREITOS CULTURAIS}

Perceber que a Constituição não é apenas e exclusivamente o texto base do ordenamento jurídico e que os juristas devem interpretá-la, mas também compreender que esse documento deve servir de fundamento e guia para os cidadãos, constitui-se na premissa elementar para se entender o contexto das inserções constitucionais dos direitos dos Povos Indígenas.

Os direitos culturais estão previstos nos artigos 210 a 216 e 231 da Constituição de 1988, nos capítulos que tratam da cultura e dos direitos dos índios. O artigo 210 aponta os conteúdos educacionais mínimos e que assegurem o respeito aos valores culturais e artísticos, nacionais, regionais e as comunidades indígenas utilizarão as línguas maternas e processos próprios de aprendizagem. Nos artigos 215 e 216 está o reconhecimento da diferença e das manifestações 
culturais indígenas. O artigo 231 reconhece aos Povos Indígenas sua organização social, costumes, línguas, crenças e tradições.

Os povos indígenas sempre reivindicaram o respeito as suas terras e cultura. A questão de concessão de terras no Brasil iniciou no século 20. No que concerne aos direitos culturais até o ano de 1926, estavam centrados à Igreja e a ação missionária. O Estado tinha como objetivo assimilá-los para a religião e cultura oficial. O Decreto n. 5.484, de 27 de junho de 1926, retirou o caráter religioso e missionário. Até 1973 o índio era considerado individualmente pelo Estado brasileiro. Com o Estatuto do Índio, Lei n. 6.001, de 1973, inseriu-se pela primeira vez o conceito de comunidade indígena e grupo tribal (artigo $3^{\circ}$, II). Ao introduzir esse conceito, a lei lhes assegurou direitos. O termo povo não é mais utilizado na legislação, mas a doutrina começou a explorá-lo como tecnicamente mais adequado.

A história da proteção legislativa dos direitos culturais no Brasil iniciou com a edição do Decreto-Lei n. 25, de 1937. A partir da Constituição de 1988 surgiram significativos avanços, reconhecendo-se no caput do artigo 216, como patrimônio cultural brasileiro todos os bens "portadores de referência à identidade, à ação, à memória dos diferentes grupos formadores da sociedade brasileira". O texto constitucional reconhece o direito à diversidade cultural no país, destacando a necessidade da proteção dos valores populares culturais.

Entende-se por direitos culturais "os valores culturais de cada povo, seus usos, costumes, tradições, identificam-no e distinguem-no dos demais, sendo essa identidade representada por bens materiais ou imateriais, que se tornam juridicamente protegidos em virtude da lei" (LEITÃO, 1993, p. 227). A Constituição de 1988, ao reconhecer a organização social, estende esse reconhecimento aos costumes, línguas, crenças e tradições e esses elementos reunidos denomina-se de 'cultura'. Os bens culturais são importantes para uma sociedade, visando-se garantir a sua preservação por meio do ordenamento jurídico interno. Trata-se de preservar e garantir a proteção dos interesses do povo, não havendo titular nominado ou exclusivo. Esse dispositivo é completamente diverso dos dispositivos constitucionais 
anteriores e que tinham caráter provisório, até que ocorresse a integração ao sistema nacional. As organizações sociais indígenas devem, para preservar a sua cultura, manter-se vigente para as gerações presentes e futuras. Seus direitos culturais passaram a integrar o patrimônio cultural brasileiro, sendo a União responsável pela proteção desses direitos e fazer com que eles sejam respeitados pela sociedade.

A Constituição de 1988 foi a primeiro documento a reconhecer que os povos indígenas têm direito a ser grupo diferenciado na sociedade brasileira, estabelecendo direitos territoriais e sociais. Reconhece que o Brasil é um país multicultural e pluriétnico, faz referência apenas aos povos indígenas, deixando de citar os quilombolas, ciganos, ribeirinhos, extrativistas em geral, fora do direito da diversidade. "Apesar dos avanços concebidos pela Constituição Federal, esse direito - ou sistemas jurídicos distintos - não foi ainda reconhecido". Mas quanto a esse aspecto, apesar das restrições, a Constituição brasileira de 1988 inovou ao reconhecer aos povos indígenas sua organização social, seus costumes e tradições.

\subsection{DIREITOS TERRITORIAIS}

O direito brasileiro regula a questão da propriedade tendo como fonte 0 direito romano, por meio dos institutos da posse e do domínio, de forma privativa e exclusiva. Necessário aqui observar que para o índio, a terra possui um valor acima do título de propriedade individual.

A Constituição de 1988, no artigo 231 reconhece que a demarcação das terras indígenas tradicionalmente ocupadas faz parte da organização social, dos costumes, das línguas, das crenças e das tradições de cada um dos povos indígenas. A relação do índio com a terra é uma relação diferenciada e peculiar. Em cada território existem características específicas e únicas. Os territórios indígenas, a partir do novo texto constitucional, "são concebidos como espaços indispensáveis ao exercício de direitos identitários desses grupos étnicos. As noções de etnia/cultura/território são, em larga medida, indissociáveis" (DUPRAT, 2019). O que 
se verifica é a larga diferença entre a propriedade privada de natureza civil, com espaço excludente e individual e o território indígena, este concebido como um espaço de acolhimento, em que o indivíduo encontra-se referido aos que o circundam.

A Constituição de 1988, no artigo 231, reconhece aos índios os direitos originários sobre as terras que tradicionalmente ocupam, sendo o "direito indígena sobre suas terras um direito dominial primário e congênito. Este direito é anterior e oponível a qualquer reconhecimento ou ocupação superveniente" (VILLARES, 2013, p. 114).

No artigo 231, $\S 1^{\circ}$ da Carta de 1988, está descrito o conceito de terras tradicionais nos seguintes termos:

São terras tradicionalmente ocupadas pelos índios as por eles habitadas em caráter permanente, as utilizadas para suas atividades produtivas, as imprescindíveis à preservação dos recursos ambientais necessários a seu bem-estar e as necessárias a sua reprodução física e cultural, segundo seus usos, costumes e tradições.

Depreende-se desse conceito que não há necessidade da imemorialidade da ocupação para a identificação de uma terra como indígena, isto é, não se vincula mais a ideia da ligação do índio que habitava as terras brasileiras desde o descobrimento do Brasil ou ocupação tão remota que não se guarda na memória até entre o ocupante atual. Os direitos originários estão na fonte do habitat natural do índio, na ligação ecológica harmoniosa do homem com a terra.

Deve-se entender por tradicional o tempo e o modo da relação dos índios com sua terra, o modo da sua ocupação, produção econômica e aproveitamento dos recursos naturais. Nesta direção também vai o conceito de ocupar, que é a forma de relacionar-se com certo território conforme os usos, costumes e tradição de cada povo indígena (VILLARES, 2013, p. 116).

Para Silva (1993, p. 47-48), o significado de tradicionalmente "refere-se não a uma circunstância temporal, mas ao modo tradicional de os índios ocuparem e utilizarem as terras e ao modo tradicional de produção, enfim, ao modo tradicional 
de como eles se relacionam com a terra". Sob este ângulo também há que frisar a existência de comunidades estáveis e outras menos estáveis, aquelas que possuem espaços territoriais maiores em que se deslocam, por isso se afirma que todos esses elementos se realizam de acordo com os seus usos, costumes e tradições.

Quando a Constituição estabelece que as terras tradicionalmente ocupadas pelos índios se destinam a sua posse permanente, significa dizer que é "garantia para o futuro, no sentido de que essas terras inalienáveis e indisponíveis são destinadas, para sempre, ao seu habitat. Se se destinam (destinar significa apontar para o futuro). à posse permanente é porque um direito sobre elas preexiste à posse mesma, e é o direito originário já mencionado" (SILVA, 1993, p. 50).

A Constituição de 1988 consagrou aos povos indígenas o reconhecimento aos índios de sua organização social, costumes, línguas e tradições, garantia explícita no artigo 231 da Carta Constitucional, tendo como objetivo precípuo desse artigo disciplinar a proteção das terras indígenas que se encontram, salvo raras exceções, em constantes ameaças. Em face disso, o legislador constituinte, após reconhecer aos índios seus direitos originários sobre as terras tradicionalmente ocupadas, também definiu o que são terras tradicionalmente ocupadas pelos índios.

O artigo 232 da Constituição Federal de 1988 prescreve norma de legitimidade para ingresso em juízo da defesa dos direitos relacionados às comunidades indígenas, natureza de direitos coletivos e não, necessariamente, os direitos individuais dos índios.

A Constituição de 1988 menciona as categorias posse permanente e usufruto exclusivo. A posse indígena, como já frisado anteriormente, não é igual àquela posse de natureza privada civil, porque esta é individual e material. A posse indígena se caracteriza por ser coletiva e é exercida de conformidade com os seus usos, costumes e tradições do povo.

Quanto à questão das terras ocupadas nos dias de hoje, deve-se observar a realidade atual e o consenso histórico sobre o tema. Como alerta Villares (2013, p. 117), "a simples constatação da inexistência de posse atual de indígenas sobre terras não retira o direito dos índios à terra, muito menos a converte em terra 
devoluta ou particular". Se há comprovação por meio de estudo antropológico que determinada área de terra é indígena, procedimentos eficientes e céleres devem ser tomados para que aquela comunidade indígena que possui o direito sobre a terra seja restabelecida e respeitada.

O direito às terras tradicionalmente ocupadas pelos índios é questão fundamental para a sobrevivência dos povos indígenas, por isso as garantias constitucionais foram declaradas com o intuito da preservação da sua cultura e tradições e vedada está a remoção dos índios de suas terras. Outro destaque quanto a esse tema é que as terras indígenas são declaradas como bens da União e consideradas bens públicos e se destinam à posse dos índios que nelas habitam e com direito ao usufruto das riquezas do solo, dos rios, lagos e não podem ser vendidas ou ter destinação diversa daquela prevista constitucionalmente. A propriedade de terras indígenas pela União é medida de proteção evitando a usurpação e exploração do patrimônio indígena.

A preocupação do constituinte com a questão indígena se concentrou na preservação do hábitat natural, isto é, das terras tradicionalmente por eles ocupadas, como condição necessária para fins de reconhecimento da sua organização social, costumes, línguas, crenças e tradições. E para que não houvesse dúvida, o constituinte também deixou claro o que se entende por terras tradicionalmente ocupadas pelos indígenas, ou seja, são aquelas terras habitadas em caráter permanente, aquelas usadas para as suas atividades produtivas, aquelas indispensáveis à preservação dos recursos ambientais fundamentais a seu bem estar e as necessárias à sua reprodução física e cultural de conformidade com os seus usos, costumes e tradições.

Depreende-se que a questão da terra é ponto fundamental dos direitos constitucionais dos indígenas, já que a terra para eles tem o significado e valor de sobrevivência física e cultural. Para Silva (1993, p. 45), "não se amparará seus direitos se não se lhes assegurar a posse permanente e a riqueza das terras por eles tradicionalmente ocupadas". E no Brasil, ainda, a disputa de terras e suas riquezas é a coluna vertebral das temáticas que envolvem os direitos indígenas. 
Outro aspecto relevante sobre direitos territoriais é a questão da demarcação de terras indígenas. A demarcação de terras indígenas é atribuição da União e tem como objetivo identificar a real extensão da posse indígena sobre as terras que tradicionalmente ocupam, a fim de que o Estado possa efetivamente proteger esses bens. O ato demarcatório tem natureza declaratória, isto é, de reconhecimento de terras indígenas.

Neste aspecto Curi (2010, p. 110) faz a crítica dizendo que, embora a demarcação seja um ato declaratório, ele é importante e deve ser concluído todo o processo por parte da União, pois o que se denota é o grande desrespeito por parte dos não índios desse dispositivo constitucional, que acabam habitando ou invadindo essas terras com o intuito econômico com a retirada dos recursos naturais, muito frequente nos casos de madeira e minérios. Nesse processo a maior dificuldade encontrada pelo Governo Federal é a retirada daqueles que ocupam terras indígenas ilegitimamente e o pagamento das indenizações de benfeitoras realizadas de boa-fé.

O processo demarcatório deve considerar, além da questão técnica, 0 sentimento do povo que habita essas terras, pois o espaço a ser demarcado oscila em razão das características culturais e os hábitos da comunidade. O estudo antropológico é requisito essencial e deve ser acompanhado também pelos índios.

Percebe-se que com o advento da Constituição de 1988, passa-se a reconhecer a categoria de direitos coletivos, com ênfase em espaço de pertencimento, em territórios, com um quadro diferente dos conceitos de propriedade privada e de institutos meramente de natureza civil, mas sim como locus étnico e cultural. Isto está delineado no artigo 216, descrevendo como espaços "onde os diversos grupos formadores da sociedade nacional têm modos próprios de expressão e de criar, fazer e viver (incisos I e II)" (DUPRAT, 2019, p. 4). A Constituição reconhece direitos específicos dos índios e quilombolas, em especial seus territórios. 


\subsection{DIREITO À AUTO-ORGANIZAÇÃO}

Autogoverno é a dimensão política da ocorrência da autodeterminação. "Os elementos essenciais de uma norma de autogoverno sui generis, desenvolvida no contexto de povos indígenas, têm base na junção de preceitos amplamente aceitos de integridade cultural e democracia, inclusive de governança local" (ANAYA, 2006, p. 192).

Quando se estabelece essa categoria significa dizer que as comunidades indígenas possuem a autonomia governamental ou administrativa local de conformidade com os seus padrões políticos e culturais históricos ou presentes, e ao mesmo tempo têm que participar de todas as decisões que os afetem e que estejam sob a direção de instituições governamentais maiores. Participação sob essa ótica exige a consulta prévia aos povos indígenas sempre que qualquer decisão venha a afetar seus interesses.

\subsection{PROTEÇÃO AOS ÍNDIOS E À COMUNIDADE}

Deve-se ter a clareza que a Carta Constitucional de 1988, ao dispor sobre a proteção aos índios e à comunidade como atribuição do poder público, não se refere à famigerada prática tutelar de outrora, porque há diferença gritante entre o termo proteção e tutela, e não se usa os diferentes conceitos como sinônimos. Nesta linha de raciocínio, Beckhaunsen (2010, p. 538) afirma que "uma atividade protetiva pode se efetivar sem a existência de qualquer prática tutelar".

O Estatuto do Índio não pode ser a única forma legal de proteção destinada aos indígenas. Outras possibilidades e formas devem ser eleitas pelo legislador.

No Código Civil de 1916, o índio era considerado como relativamente capaz. O Estatuto do Índio submete o índio à tutela do Estado, tais dispositivos não foram abarcados pela Constituição Federal de 1988.

O Código Civil brasileiro de 2002 trouxe um tratamento mais positivo aos índios, prescrevendo que o tema capacidade para a prática de atos da vida civil 
deve ser matéria de lei específica, isto é, não há no Código Civil menção à relativa capacidade dos índios, não menciona a tutela de índios e o termo silvícola. No artigo $4^{\circ}$ é feita referência à capacidade "relativa" dos índios, que deverá ser regulada por legislação especial.

Dessa forma, há que considerar a inovação, mas remeteu às questões indígenas a regramento específico, enquanto essa legislação especial não é criada. Infelizmente ainda prevalecem as regras previstas no Estatuto do Índio como instrumento de normas a orientar a atuação do Estado. $O$ instituto da tutela como está prescrito no Código Civil não se aplica às populações indígenas, há que se estabelecer um regime de proteção diferenciado, "que não trate os índios como indivíduos deficientes, mas como pessoas que necessitam de estatuto jurídico especial" (ARAÚJO, 2006, p. 56).

$\mathrm{Na}$ realidade, o que se percebe é que o Estado também é um mau tutor, e a ideia ultrapassada de tutela ainda tem seus resquícios assimilacionistas nos dias atuais.

As previsões do Estatuto do Índio no que diz respeito ao poder tutelar estão em desacordo com a previsão do atual texto constitucional. A Constituição Federal de 1988 estabelece, no artigo 232 que "Os índios, suas comunidades e organizações são partes legítimas para ingressar em juízo em defesa de seus direitos e interesses, intervindo o Ministério Público em todos os atos do processo".

Com a edição do artigo 232 da Carta Constitucional os índios individualmente e não mais só coletivamente podem ingressar em juízo na defesa de seus interesses. Isso significa a plena capacidade civil do indígena, não havendo mais a necessidade de ser assistido em juízo pelo Ministério Público Federal e FUNAI. O Ministério Público passa a intervir apenas na condição de fiscal da lei. Caiu por terra a ideia de tutela.

Está claro que a ideia de integrar os indivíduos que assim o desejam na vida nacional ficou mantida em toda a sua plenitude. Integrando-se ou não, o Estado nacional reconhece o direito de continuar a ser índio, coletivamente entendido, de continuar a ser grupo diferenciado, sociedade externamente organizada, um antigo 
lema indígena equatoriano 'puedo ser lo que eres sindejar de lo que soy'. Está rompida a provisoriedade que regeu toda a política indigenista dos quinhentos anos de contrato.

No entanto, há que se reconhecer que a Constituição de 1988 inovou, ao tratar dos direitos fundamentais dos povos indígenas, ultrapassando a ideologia da tutela ao reconhecer a capacidade civil dos indígenas. Deixou para trás a visão integracionista e estabelece como princípio o direito à diferença sociocultural dos povos indígenas, reconhece igualmente a autonomia dos povos indígenas, garantindo o direito ao território, à cultura, à educação, ao desenvolvimento econômico, em conformidade com seus projetos presentes e futuros e, por fim, o reconhecimento do direito à cidadania híbrida, isto é, étnica, nacional e global (AMATO, 2014, p. 209).

Na proposta do Estatuto do Estatuto dos Povos Indígenas, o tema central de mudança é o da capacidade civil dos índios e alterações do atual sistema tutelar. Há diversas propostas nesta direção, no entanto essas propostas são rebatidas sob o argumento que a FUNAI, criada para fazer o papel de tutor, estaria fadada à extinção, e os índios ficariam desprotegidos (ARAúJO, 2006, p. 45). O que se propõe efetivamente é a substituição da tutela por outros mecanismos de proteção especial e instrumentos de apoio do poder público aos Povos Indígenas.

\section{CONCLUSÃO}

A história indigenista brasileira traz registros importantes. Um deles, é que por muito tempo o tratamento jurídico conferido aos Povos Indígenas vinculou-se à ideia de que eles constituíam obstáculos ao desenvolvimento do país, porque não se curvavam aos interesses políticos e econômicos então predominantes. Nesse sentido, o presente estudo revela que as determinações contidas nas diversas Constituições - anteriores à Carta de 1988 - compreendendo o período colonial até o século 20, simplesmente se omitiram de promover a tutela de proteção e dos interesses das comunidades indígenas. Ao contrário, tratavam os Povos Indígenas 
com preconceitos e discriminações, deixando de atender as necessidades mais básicas de sua peculiar existência. Com a promulgação da Constituição de 1988, o reconhecimento dos direitos indígenas apresentou novos contornos e com interessantes inovações.

Atualmente, os direitos constitucionais dos índios estão previstos na Constituição Federal Brasileira de 1988, na parte da Ordem Social, no capítulo VIII, intitulado "Dos índios", em outros dispositivos esparsos e no Ato das Disposições Constitucionais Transitórias. Finalmente, a Carta Constitucional abandonou a antiga perspectiva assimilacionista, que entendia os indígenas como categoria social transitória e com tendência a desaparecer com passar do tempo.

Outra importante inovação diz respeito ao direito às terras indígenas, entendendo-o como um direito originário, anterior à criação do Estado. Com essa previsão constitucional passou-se a reconhecer o fato histórico de que os índios foram os primeiros habitantes das terras brasileiras. Nesse contexto, os direitos indígenas têm a função não apenas de reconhecer a existência das comunidades nativas, mas de assegurar o respeito ao seu modo diferente de viver no mundo. Os direitos à vida, à igualdade, à liberdade, à segurança e à propriedade, previstos no artigo $5^{\circ}$ da Constituição Federal, constituem-se em direitos elementares dos indígenas e o seu cumprimento é atribuição de incumbência da União Federal.

A partir desse novo tratamento constitucional, as relações entre o Estado, sociedade brasileira e os povos indígenas tomam outra direção, assegurando respeito à sua organização social, costumes, crenças, tradições e o direito à diferença, previsto no artigo 231 da Constituição Federal. O novo texto constitucional introduziu cláusulas de reconhecimento e sedimentou o critério de respeito dos direitos dos povos indígenas. Em específico, os direitos vinculados as suas naturais terras, territórios e recursos.

Esse processo de reconhecimento foi constituído lado a lado com as reformas constitucionais de 1988, que de alguma forma reconhecem a composição multiétnica e pluricultural das sociedades latino-americanas, e ao menos retoricamente, deixaram para trás as políticas integracionistas ou assimilacionistas 
anteriores, por uma nova fase denominada multiculturalista.

Antes da Constituição de 1988, os direitos dos povos indígenas eram de natureza transitória, já que esses direitos eram "garantidos" em termos legais até que os índios entrassem para a categoria de "civilizados". A partir de 1988, os direitos passaram a ser de natureza permanente, assegurando aos povos indígenas a manutenção de sua cultura e a legitimação de suas características próprias e diferenciadas. Com a Constituição de 1988 iniciou-se novo debate a respeito das mudanças que se faziam e se fazem necessárias em relação aos direitos dos Povos Indígenas no Brasil.

Quanto à relevância das diretrizes da Carta de 1988, ressalta-se que os direitos dos Povos Indígenas foram sendo conquistados e amadurecidos no curso de uma história nem sempre justa e generosa que, por muito tempo, sequer permitiu aos índios se fazerem ouvir.

Panorama que aos poucos se modifica para dar lugar a um protagonismo exercido amplamente pelos Povos Indígenas e suas organizações junto a outros setores da sociedade que sempre os apoiaram. Os Povos Indígenas buscam a cada dia colocar a lei em prática. O objetivo é encontrar, para além do formalismo das instituições e normas, as soluções para a implantação de seus direitos e para a garantia da viabilidade de seus projetos de um futuro sustentável.

Contudo, embora exista uma legislação vigente no país para tratar dos direitos dos Povos Indígenas, existe também grande lacuna entre a teoria e a prática, legitimada principalmente pela postura preconceituosa da sociedade envolvente, que continua enxergando os indígenas como povos inferiores. Por outro lado, são inúmeras as dificuldades enfrentadas pelos povos indígenas para assegurar seus direitos frente ao poderio econômico, que desconsidera o direito originário desses povos sobre as terras que tradicionalmente ocupam.

Em que pese todo o arcabouço de direitos e leis previstas no ordenamento jurídico brasileiro, em especial, as interessantes inovações introduzidas pela Constituição de 1988, há muito a ser feito para que os direitos dos Povos Indígenas sejam efetivados. 
Constata-se, que na sociedade brasileira ainda há o preconceito, a discriminação e a exclusão do indígena. Precisa-se avançar para que sejam respeitados os direitos dos Povos indígenas de manter e reforçar suas próprias instituições, culturas e tradições, além de prosseguir com seu desenvolvimento em sintonia com suas necessidades e aspirações. A realidade cultural requer novos enfoques e medidas no que diz respeito aos problemas globais, tais como desenvolvimento, descentralização e democracia multicultural.

O grande desafio a ser enfrentado é a concretização dos direitos estabelecidos na atual Carta constitucional de 1988, somando-se seu pleno reconhecimento, para fazer valer o respeito aos Povos Indígenas, as suas vidas, as suas culturas e as suas peculiares formas de organização.

\section{REFERÊNCIAS}

ARAÚJO, Ana Valéria. Direitos indígenas no Brasil: breve relato de sua evolução histórica. In: ARAÚJO, Ana Valéria et al. Povos indígenas e a lei dos "brancos": o direito à diferença. Brasília: Ministério da Educação, Secretaria de Educação Continuada, Alfabetização e Diversidade. LACED/Museu Nacional, 2006.

BECKHAUSEN, Marcelo. Etnocidadania, direitos originários e a inconstitucionalidade do poder tutelar. In: SARMENTO, Daniel; IKAWA, Daniela; PIOVESAN, Flávia. Igualdade, diferenças e direitos humanos. Rio de Janeiro: Lumen Juris, 2010.

BONAVIDES, Paulo; ANDRADE, Paes de. História constitucional do Brasil. 3. ed. Rio de Janeiro: Paz e Terra, 1991.

BRASIL. Constituição (1988). Constituição da República Federativa do Brasil. Disponível em: <www.planalto.gov.br>. Acesso em: 14 abril 2019.

COLAÇO, Thais Luzia. O direito indígena a partir da Constituição brasileira de 1988. In: WOLKMER, Antonio Carlos; MELO, Milena Petters (Orgs.). Constitucionalismo latino-americano: tendências contemporâneas. Curitiba: Juruá, 2013.

. Os "novos" direitos indígenas. In: Wolkmer, Antônio Carlos; Leite, José Rubens Morato (Orgs.). Os 'novos' direitos no Brasil - natureza e perspectivas: uma visão básica das novas conflituosidades jurídicas. 2. ed. São Paulo: Saraiva, 
2012, v. 1.

BRAUN, Helenice da Aparecida Dambrós. Os indígenas e seus diretos trabalhistas: uma análise de demandas judiciais de comunidades em Chapecó. Curitiba: CRV, 2017.

COMTE, Augusto. Discurso sobre o espírito positivo: ordem e progresso. Tradução de Renato Barbosa Rodrigues Pereira. São Paulo: USP, 1976.

CURI, Melissa Volpato. Os direitos indígenas e a Constituição Federal. Consilium Revista Eletrônica de Direito. Brasília n. 4, v. 1 maio/ago. de 2010. Disponível em: <http://www.unieuro.edu.br/sitenovo/revistas/downloads/consilium_04_03.pdf>. Acesso em: 14 abril 2019.

DUPRAT, Deborah. Terras indígenas e 0 judiciário. Disponível em: <http://www.mpf.mp.br/atuacao-tematica/ccr6/documentos-epublicacoes/artigos/docs/artigos/docs_artigos/terras_indigenas_e_o_judiciario.pdf>. Acesso em: 14 abril 2019.

FUNDAÇÃO NACIONAL DO INDIO. FUNAI. Índios no Brasil. Disponível em: $<$ http://www.funai.gov.br/index.php/indios-no-brasil/quem-sao>. Acesso em: 12 abril 2019.

HENRIQUES, Miguel Barreto. A especificidade dos direitos dos povos indígenas e os limites do sistema internacional e latino-americano de protecção de direitos humanos. RAI - Revista Analisis Internacional. 9. v. 5. N. 1, Enero-junio, 2014.

INSTITUTO BRASILEIRO DE GEOGRAFIA E ESTATÍSTICA. IBGE. Indígenas. Disponível em: <http://indigenas.ibge.gov.br/graficos-e-tabelas-2.html>. Acesso em: 10 abril 2019.

IKAWA, Daniela. Direito dos povos indígenas. In: SARMENTO, Daniel; IKAWA, Daniela; PIOVESAN, Flávia (Coord.). Igualdade, diferença e direitos humanos. Rio de Janeiro: Lumen Juris, 2010.

LEITÃO, Ana Valéria do Nascimento Araújo. Direitos culturais dos povos indígenas: aspectos do seu reconhecimento. In: SANTILLI, Juliana (Coord.). Os direitos indígenas e a Constituição. Porto Alegre: Núcleo de Direitos Indígenas e Sergio Antonio Fabris, 1993.

LOPES, DANIELLE BASTOS. O direito dos índios no Brasil: a trajetória dos grupos indígenas nas Constituições do país. UERJ, p.83-108. Espaço Ameríndio, Porto Alegre, v. 8, n. 1, p. 83-108, jan./jun. 2014.

Disponível em: https://seer.ufrgs.br/EspacoAmerindio/article/download/41524/29955. Acesso em: 14 abril 2019. 
PORTAL BRASIL. No Brasil população indígena é de 896, 9 mil. Disponível em: $<$ http://www.brasil.gov.br/governo/2015/04/populacao-indigena-no-brasil-e-de-896-9mil>. Acesso em: 14 abril 2019.

POVOS INDÍGENAS NO BRASIL. Disponível em: $<$ https://pib.socioambiental.org/pt/povo/kaingang/283>. Acesso em: 14 abril 2019.

SILVA, José Afonso da. Terras tradicionalmente ocupadas pelos índios. In: SANTILLI, Juliana (Coord.). Os direitos indígenas e a Constituição. Porto Alegre: Núcleo de Direitos Indígenas e Sergio Antonio Fabris, 1993.

SOUZA, Manoel Nascimento de Souza. BARBOSA, Erivaldo Moreira. Direitos indígenas fundamentais e sua tutela na ordem jurídica brasileira. Disponível em: <http://www.ambito-juridico.com.br>. Acesso em: 22 jul. 2015.

VILLARES, Luiz Fernando. Direito e povos indígenas. Curitiba: Juruá, 2013. 